(C) [2010] IEEE. Reprinted, with permission, from [Benedykt Rodanski, A novel design of active inductors based on current controlled voltage sources, Symbolic and Numerical Methods, Modeling and Applications to Circuit Design (SM2ACD), 2010 XIth International Workshop on, 4-6 Oct. 2010]. This material is posted here with permission of the IEEE. Such permission of the IEEE does not in any way imply IEEE endorsement of any of the University of Technology, Sydney's products or services. Internal or personal use of this material is permitted. However, permission to reprint/republish this material for advertising or promotional purposes or for creating new collective works for resale or redistribution must be obtained from the IEEE by writing to pubs-permissions@ieee.org. By choosing to view this document, you agree to all provisions of the copyright laws protecting it 


\section{A Novel Design of Active Inductors based on Current Controlled Voltage Sources}

\author{
Marian Pierzchała \\ Wroclaw Univ. of Technology \\ Wroclaw, Poland \\ marian.pierzchala@pwr.wroc.pl
}

\author{
Mourad Fakhfakh \\ University of Sfax, \\ Sfax, Tunisia \\ mourad.fakhfakh@ieee.org
}

\author{
Benedykt Rodanski \\ University of Technology \\ Sydney, Australia \\ ben.rodanski@uts.edu.au
}

\begin{abstract}
This brief presents a new structure of active inductors. These synthetic inductors are designed using current controlled voltage sources. The signal flow graph method is used for this purpose. For the practical realization, operational transresistance amplifiers (OTRAs) are replicated using current conveyors. The proposed inductors have very interesting properties because the value of its inductance is proportional to the product of the parameter of the OTRAs $\left(r_{m 1} r_{m 2}\right)$ and thus, small capacitor values can be used. Current conveyor based simulated inductors are presented and SPICE simulations are given to show the viability of the proposed synthesis technique.
\end{abstract}

\section{INTRODUCTION}

There exist many techniques for generating structures of active inductors, i.e. circuits which have the properties of classical inductors but that are built using only capacitors and active sources. The very popular configuration of such active inductors comprises two transconductance amplifiers (OTA circuits) and one capacitor $\left(g_{m}-C\right.$ circuit) [1]. However, the equivalent inductance value $L$ of this circuit is inversely proportional to the parameters of the OTA circuits $\left(g_{m 1}, g_{m 2}\right)$ and this is a drawback of the circuit. In order to eliminate this drawback, an active inductor configuration using current controlled voltage sources was proposed in [2], where the value of the inductance $L$ is proportional to the product of the parameters $\left(r_{m 1} r_{m 2}\right)$ of the controlled sources. However, this configuration is complicated because it uses additional active elements. In this paper we propose a simpler configuration of active inductors based on the use of transresitance operational amplifiers. The proposed active inductor comprises only two OTRA circuits and one capacitor.

\section{ACTIVE INDUCTORS}

\section{A. $g_{m}-C$ circuits}

Many electronic circuits are based on the use of simulated inductors. This is argued by the well known drawbacks of the spiral inductors, such as occupied silicon area, tunability, etc. The basic idea behind designing such inductors is to create an impedance that looks inductive, using only capacitors and active devices. The transconductance amplifier or transconductor (OTA circuit) has become prominent in filter design because of its tunability and its good high-frequency response [1]. Figure 1 presents an OTA-based grounded active inductor. For designing floating synthetic inductors, OTAs with differential outputs are used, as shown in Figure 2.

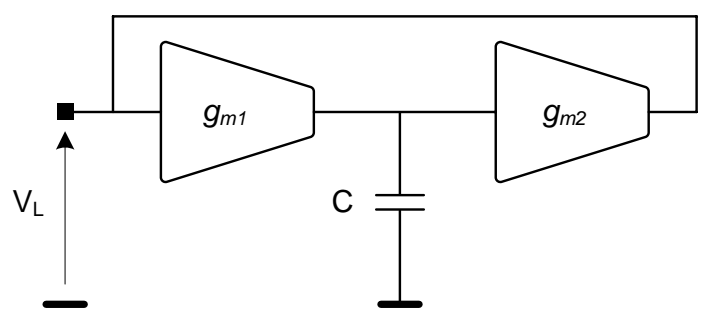

Figure 1. The OTA-based grounded simulated inductor.

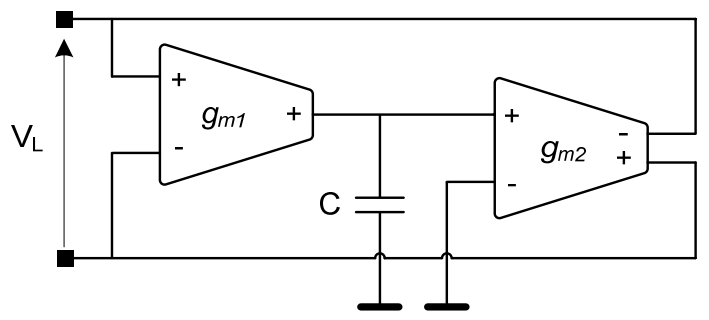

Figure 2. The OTA-based floating active inductor.

The simulated inductance value $L$ in these configurations is given by

$$
L=\frac{C}{g_{m 1} g_{m 2}}
$$

So, it is inversely proportional to the parameter of the OTA circuits. This, actually, this is a drawback.

Indeed, calculating the relative change of the inductance in (1) shows that for the negative changes of the OTA 
parameters, i.e. $\left(-\Delta g_{m 1},-\Delta g_{m 2}\right)$, we obtain large relative changes of the inductor value $L$ :

$$
\begin{aligned}
\frac{\Delta L}{L}= & \frac{\frac{\Delta C}{C}-\frac{\Delta g_{m 1}}{g_{m 1}}-\frac{\Delta g_{m 2}}{g_{m 2}}-\frac{\Delta g_{m 1} \Delta g_{m 2}}{g_{m 1} g_{m 2}}}{\left(1+\frac{\Delta g_{m 1}}{g_{m 1}}\right)\left(1+\frac{\Delta g_{m 2}}{g_{m 2}}\right)} \\
& \approx \frac{\frac{\Delta C}{C}-\frac{\Delta g_{m 1}}{g_{m 1}}-\frac{\Delta g_{m 2}}{g_{m 2}}}{1+\frac{\Delta g_{m 1}}{g_{m 1}}+\frac{\Delta g_{m 2}}{g_{m 2}}}
\end{aligned}
$$

\section{B. $r_{m}-C$ circuits}

Recently, a new structure of active inductors using current controlled voltage sources was proposed in [2]. It is based on the signal flow graph presented in Figure 3.

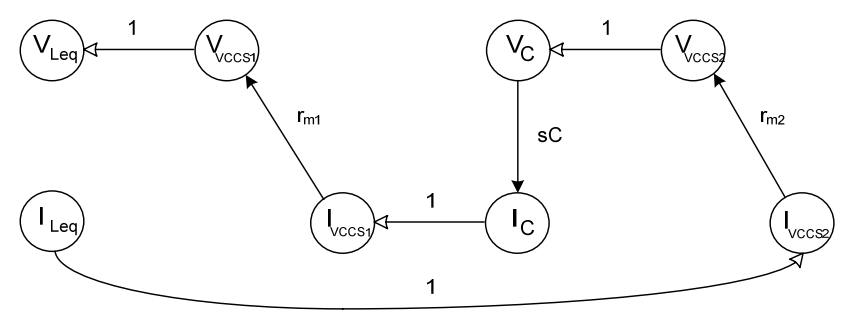

Figure 3. The signal flow graph of the active inductor with current controlled voltage sources.

The circuit corresponding to that graph can be described by the following expressions:

$$
\begin{gathered}
V_{L_{e q}}=s C r_{m 1} r_{m 2} I_{L_{e q}} \\
L_{e q}=C r_{m 1} r_{m 2}
\end{gathered}
$$

This circuit offers a very interesting property because the value of the simulated inductance $L$ is proportional to the product of the parameters of the current controlled voltage sources $\left(r_{m 1} r_{m 2}\right)$ and thus, the inductance values of the simulated inductor can be designed using small capacitances of capacitor $C$. Moreover, the relative change of the inductance

$$
\begin{aligned}
\frac{\Delta L}{L} & =\frac{\Delta C}{C}\left(1+\frac{\Delta r_{m 1}}{r_{m 1}}+\frac{\Delta r_{m 2}}{r_{m 2}}+\frac{\Delta r_{m 1} \Delta r_{m 2}}{r_{m 1} r_{m 2}}\right) \\
& +\frac{\Delta r_{m 1}}{r_{m 1}}+\frac{\Delta r_{m 2}}{r_{m 2}}+\frac{\Delta r_{m 1} \Delta r_{m 2}}{r_{m 1} r_{m 2}} \\
& \approx \frac{\Delta C}{C}+\frac{\Delta r_{m 1}}{r_{m 1}}+\frac{\Delta r_{m 2}}{r_{m 2}}
\end{aligned}
$$

is relatively smaller than the one of the OTA-based circuits.

Using the graph presented in Figure 3, a "switched" current controlled voltage source (CCVS) circuit was proposed in [1]. It is shown in Figure 4.

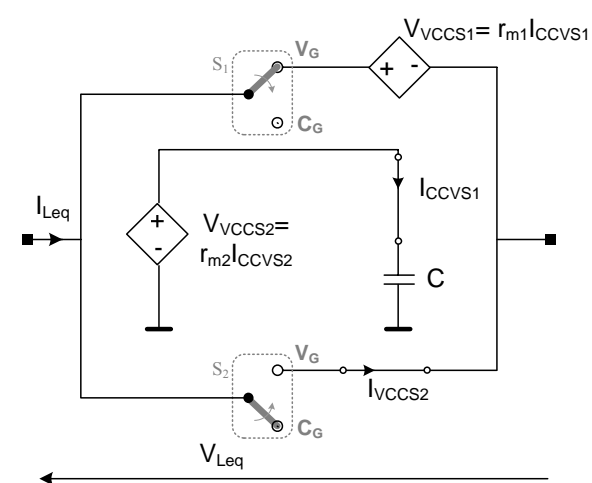

Figure 4. An active inductor with current controlled voltage sources and special kind of switches

In Figure 4 the switches are controlled by the type of the graph. For the voltage graph the switch $S_{1}$ is a short-circuit and $S_{2}$ is an open-circuit. For the current graph $S_{1}$ is an opencircuit, whereas $S_{2}$ is a short-circuit. According to the "switched" circuit presented in Figure 4, a nullator/norator based circuit can be realized [3]. It is shown in Figure 5.

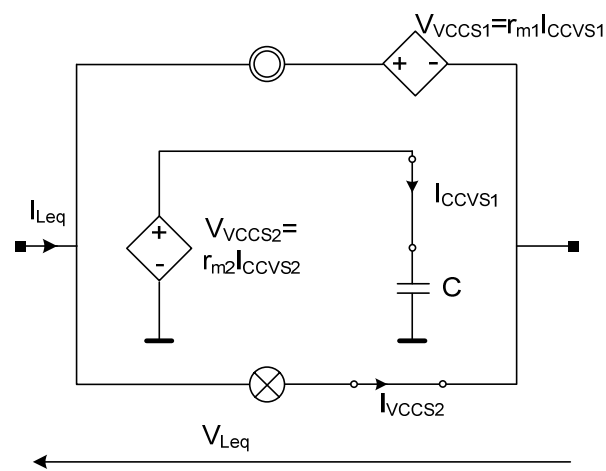

Figure 5. An active inductor with a nullator, a nullator and a current controlled voltage source.

However, this circuit is complicated; it necessitates the use of an additional CCII- to perform 'switching' between the voltage graph and the current graph. In the following, we propose an improved CCVS-based structure of such synthetic inductors that does not use switches; i.e. the nullator and the norator.

\section{THE PROPOSED CIRCUIT}

The signal flow graph presented in Figure 3 can also be realized as proposed in Figure 6. This configuration uses only current controlled voltage sources, i.e. no 'switches' are needed. Figure 7 presents the new circuit, where OTRAs are used to design the CCVSs. 


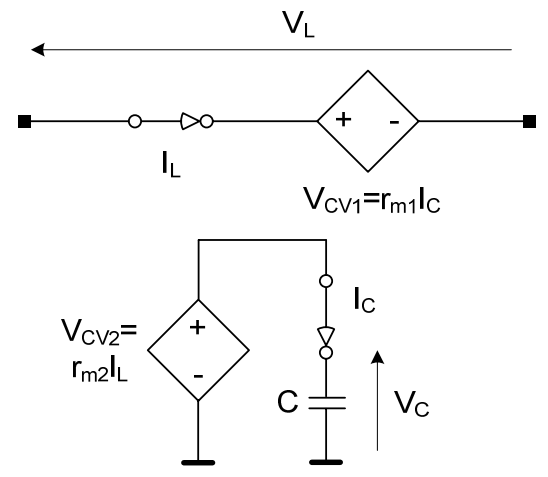

Figure 6. The new circuit realization of the signal flow graph presented in Figure 3.

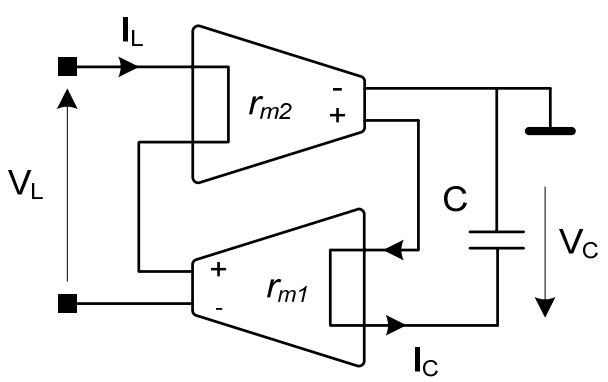

Figure 7. The OTRA-based circuit of the floating inductor.

It is clear, according to Figure 7, that the second OTRA can be a classical one with a single-ended output. Similarly, the grounded inductor can be designed using two classical OTRA circuits with single-ended outputs, as shown in Figure 8.

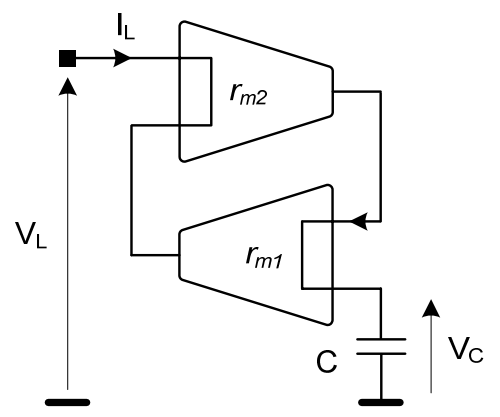

Figure 8. The OTRA-based circuit of the grounded inductor.

\section{The Practical Realization}

The proposed active inductor presented in Figure 7 was designed using negative second generation current conveyors (CCII-), replicating the transresistance amplifiers. Indeed, it was shown in $[4,5]$ that controlled sources can be designed using nullors and resistors. In addition, it has been proven that the nullor can be considered a universal element, thus it can reproduce the ideal behavior of an ideal current conveyor. Figure 9 shows the nullor based CCVS and its implementation using CCII-s.

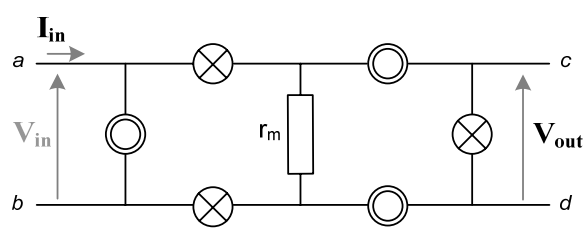

(a)

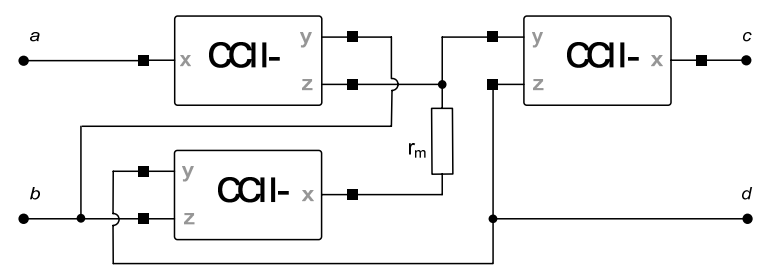

(b)

Figure 9. (a): The nullor based CCVS, (b): Its implementation using CCII-s

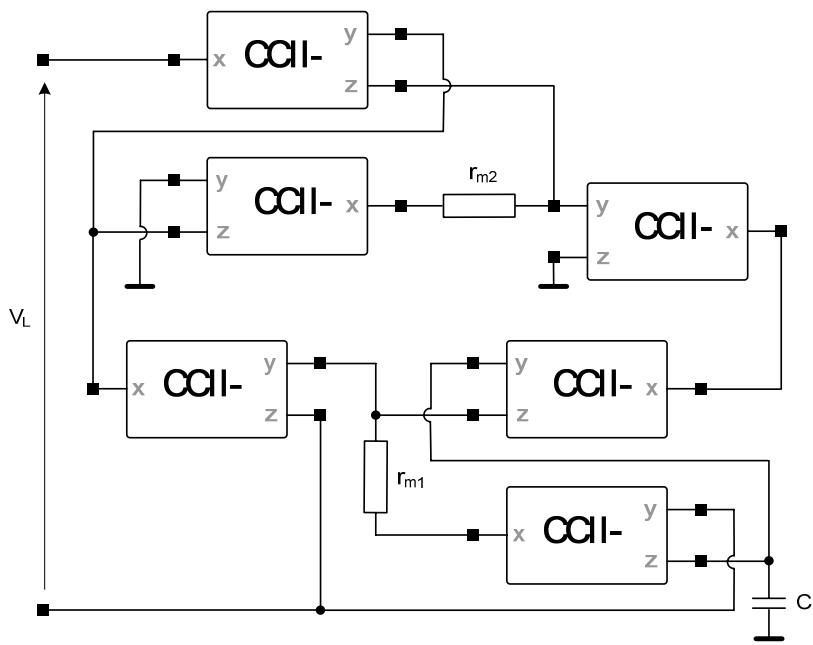

Figure 10. The CCII- based active inductor.

Figures 11-14 present SPICE simulation results $\left(\left(V_{\text {Leq }} / I_{\text {Leq }}\right)_{\mathrm{dB}}\right)$ performed using a CMOS CCII- [6]. Respective inductances are $1 \mathrm{H}, 100 \mathrm{mH}, 10 \mathrm{mH}$ and $1 \mathrm{mH}$, for values of the capacitors, respectively: $1 \mu \mathrm{F}, 100 \mathrm{nF}, 10 \mathrm{nF}$ and $1 \mathrm{nF}$. Technology under consideration is AMS $0.35 \mu \mathrm{m}$. Supply voltage is $\pm 1.5 \mathrm{~V} ; r_{m 1}=r_{m 2}=10 \mathrm{k} \Omega$. The broken line curves represent simulation of the ideal inductor (solid line).

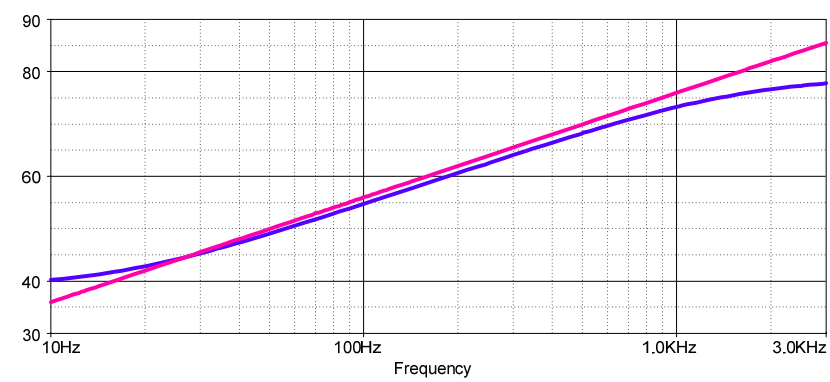

Figure 11. SPICE simulations for $\mathrm{L}=1 \mathrm{H}(\mathrm{C}=1 \mu \mathrm{F})$. 


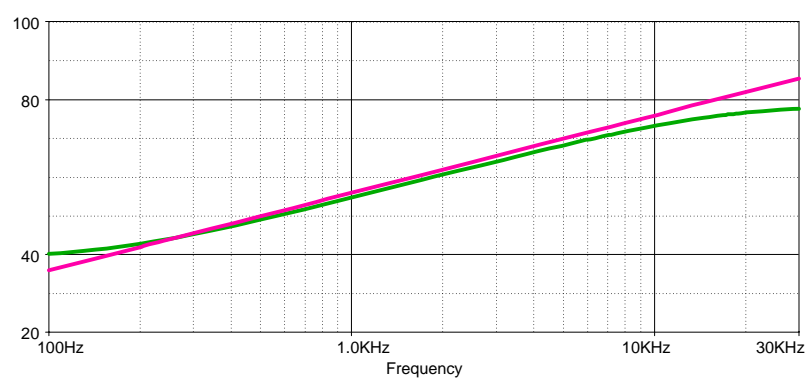

Figure 12. SPICE simulations for $\mathrm{L}=100 \mathrm{mH}(\mathrm{C}=100 \mathrm{nF})$.

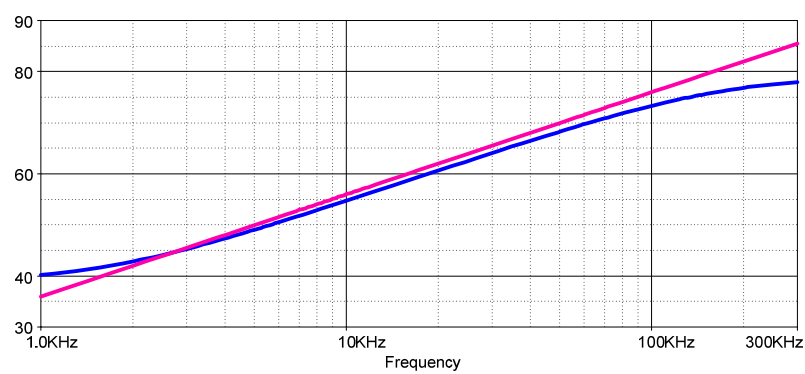

Figure 13. SPICE simulations for $\mathrm{L}=10 \mathrm{mH}(\mathrm{C}=10 \mathrm{nF})$.

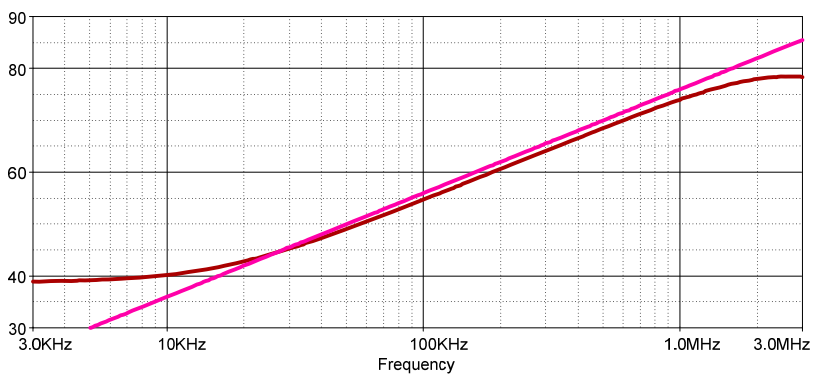

Figure 14. SPICE simulations for $\mathrm{L}=1 \mathrm{mH}(\mathrm{C}=1 \mathrm{nF})$.

\section{CONCLUSION}

This paper presented a novel active inductor structures which design is based on the use of current controlled voltage sources. The signal flow-graph is used for this purpose. The proposed circuit was designed using OTRAs. It was shown that the new circuit offers better performances when compared to the conventional OTA-based simulated inductors. In order to highlight viability of the new synthetic inductor, current controlled voltage sources were designed using negative second generation CMOS current conveyors, and SPICE simulations were given. The basic idea behind designing the circuit using current conveyors is the nullor based controlled sources design. Thus, for higher performance inductors, mainly in terms of operating frequencies, such inductors can be designed directly using MOS transistors.

\section{REFERENCES}

[1] D. Comer and D. Comer, Advanced Electronic Circuit Design, John Wiley \& Sons, Inc. 2003, pp. 472-474.

[2] M. Pierzchala and M. Fakhfakh, "Generation of the Active Inductor Circuits," The IEEE International Symposium on Circuits and Systems. (ISCAS), May/June 2010. Paris, France.

[3] B. Rodanski, "Extension of the two-graph method for symbolic analysis of of circuits with non-admittance elements", The International Workshop on Symbolic Methods and Applications to Circuit Design (SMACD), October 2002. Sinaia, Romania.

[4] J.A. Svoboda, "Using nullors to analyse linear networks", International Journal of Circuit Theory and Applications, vol. 14, pp. 169-180, 1986.

[5] C. Sánchez-López, "Modeling Active Devices With Nullor For Analog Signal Processing", in Design of Analog Circuits through Symbolic Analysis, M. Fakhfakh, E. Tlelo-Cuautle and F. V. Fernandez (Eds), Bentham publisher, 2010.

[6] M. Fakhfakh, M. Loulou and E. Tlelo-Cuautle, "Synthesis of CCIIs and design of simulated CCII based floating inductances", The IEEE International Conference on Electronics, Circuits and Systems (ICECS), December 2007. Marrakech, Morocco. 